\title{
IL-21 drives secondary autoimmunity in patients with multiple sclerosis, following therapeutic lymphocyte depletion with alemtuzumab (Campath-1H)
}

\author{
Joanne L. Jones, Chia-Ling Phuah, Amanda L. Cox, Sara A. Thompson, Maria Ban, \\ Jacqueline Shawcross, Amie Walton, Stephen J. Sawcer, Alastair Compston, and Alasdair J. Coles \\ Department of Clinical Neuroscience, University of Cambridge, Addenbrooke's Hospital, Cambridge, United Kingdom.
}

\begin{abstract}
Phase II clinical trials revealed that the lymphocyte-depleting humanized monoclonal antibody alemtuzumab (Campath-1H) is highly effective in the treatment of early relapsing-remitting multiple sclerosis. However, $30 \%$ of patients develop autoimmunity months to years after pulsed exposure to alemtuzumab, usually targeting the thyroid gland and, more rarely, blood components. In this study, we show that autoimmunity arose in those patients with greater $T$ cell apoptosis and cell cycling in response to alemtuzumab-induced lymphocyte depletion, a phenomenon that is driven by higher levels of IL-21. Before treatment, patients who went on to develop secondary autoimmunity had more than 2 -fold greater levels of serum IL-21 than the nonautoimmune group. We suggest that serum IL-21 may, therefore, serve as a biomarker for the risk of developing autoimmunity months to years after alemtuzumab treatment. This has implications for counseling those patients with multiple sclerosis who are considering lymphocyte-depleting therapy with alemtuzumab. Finally, we demonstrate through genotyping that IL-21 expression is genetically predetermined. We propose that, by driving cycles of T cell expansion and apoptosis to excess, IL-21 increases the stochastic opportunities for T cells to encounter self antigen and, hence, for autoimmunity.
\end{abstract}

\section{Introduction}

Autoimmunity arising in the context of lymphopenia is well recognized experimentally but rarely encountered and, hence, difficult to study in humans. We have identified an example of predictable autoimmunity in humans, arising after treatment of multiple sclerosis with the lymphocyte-depleting monoclonal antibody alemtuzumab. This human "model" provides a unique opportunity to explore the immunological mechanisms underlying the development of lymphopenia-associated autoimmunity in humans.

Alemtuzumab, licensed for the treatment of B cell chronic lymphocytic leukemia, is a humanized monoclonal antibody directed against CD52, a protein widely distributed on the surface of lymphocytes and monocytes but with unknown function. A single pulse of treatment leads to a rapid, profound, and prolonged lymphopenia. Cell numbers recover but at varying rates; $\mathrm{CD}^{+} \mathrm{T}$ cells are particularly slow to recover, remaining depleted for at least 5 years (1). A recently published phase II trial has shown that alemtuzumab reduces the risk of disease activity and accumulation of disability by over $70 \%$ compared with interferon beta in patients with early relapsing-remitting multiple sclerosis (2). The principal adverse effect is autoimmunity, arising in the setting of $\mathrm{T}$ cell

Conflict of interest: Joanne L. Jones reports receiving consulting fees and lecture fees from Bayer Schering Pharma. Alasdair J. Coles reports receiving consulting fees, lecture fees, and grant support from Genzyme. Alastair Compston reports receiving consulting fees, lecture fees, and grant support from Genzyme and lecture fees from Bayer Schering Pharma.

Nonstandard abbreviations used: ITP, idiopathic thrombocytopenic purpura; MBP, myelin basic protein; rhIL-21, recombinant human IL-21; TSHr, thyroid-stimulating hormone receptor.

Citation for this article: J. Clin. Invest. 119:2052-2061 (2009). doi:10.1172/JCI37878. lymphopenia months to years after alemtuzumab: $20 \%-30 \%$ of patients develop thyroid autoimmunity, mainly Graves disease (3), and 3\% have idiopathic thrombocytopenic purpura (ITP) (2). We have also observed 2 cases of Goodpasture disease and 1 case each of autoimmune neutropenia (1) and autoimmune hemolytic anaemia (Alasdair J. Coles, personal communication). In addition, a further $5.5 \%$ of patients develop sustained nonthyroid autoantibodies without clinical disease (1). The timing and spectrum of autoimmunity after alemtuzumab is similar to that seen in other examples of "reconstitution autoimmunity" in other clinical contexts; for example, autoimmune thyroid disease and autoimmune cytopenias also predominate months to years after hematopoietic stem cell transplantation or antiretroviral treatment of HIV (4-8).

While the association between lymphopenia and autoimmunity is well recognized, most lymphopenic subjects do not develop autoimmunity, leading Krupica et al. to postulate that additional factors are involved (9). Among the secondary insults suggested by this group are (a) the depletion of Tregs, as seen in the murine colitis and gastritis models (10-13), and (b) overproduction of IL-21, as occurs in the NOD mouse (14). We have previously disproved the first possibility: in the context of multiple sclerosis treatment by alemtuzumab, $\mathrm{CD} 4{ }^{+} \mathrm{CD} 25^{\text {hi }}$ Tregs and lymphocyte FoxP3 expression are both increased for 6 months after treatment and thereafter return to normal levels (15). This observation has since been replicated (16) and is in keeping with other experimental lymphopenic models $(17,18)$. So, we have turned to the second suggestion, which arose from the observation that autoimmunity in the NOD mouse is associated with increased $\mathrm{T}$ cell cycling and reduced $\mathrm{T}$ cell survival, driven by overproduction of IL-21 (14). Here, we show that a similar process underlies human 
A Apoptosis/proliferation studies (fresh ex vivo samples)

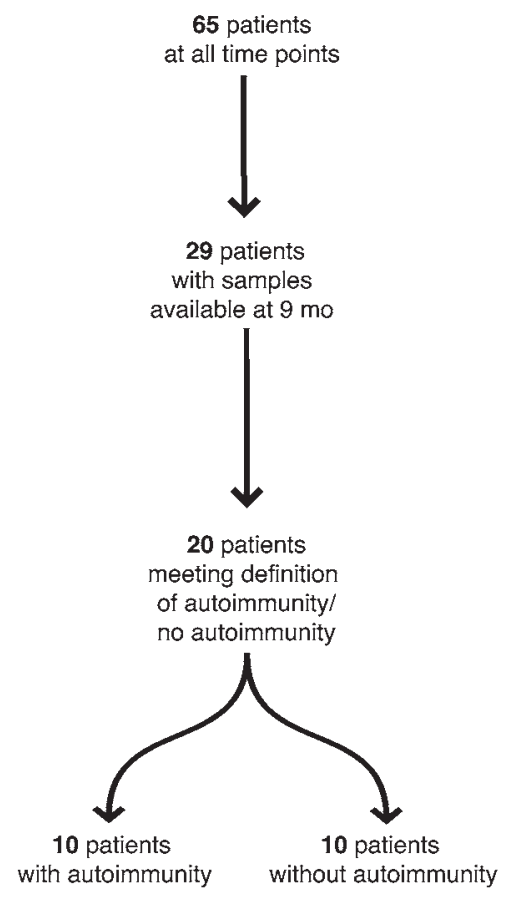

B

\section{Serum IL-21 studies} (frozen samples)

94 patients with pretreatment serum available

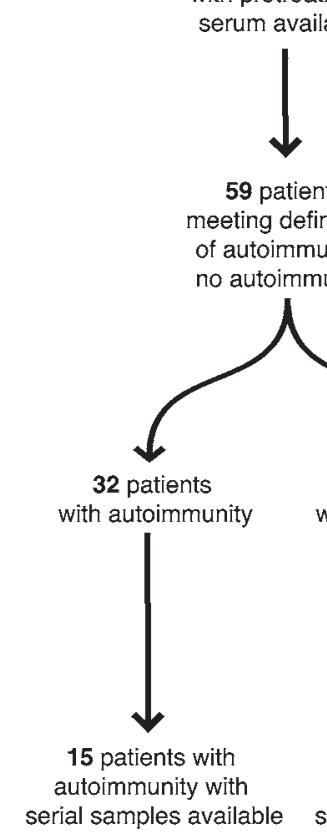

C

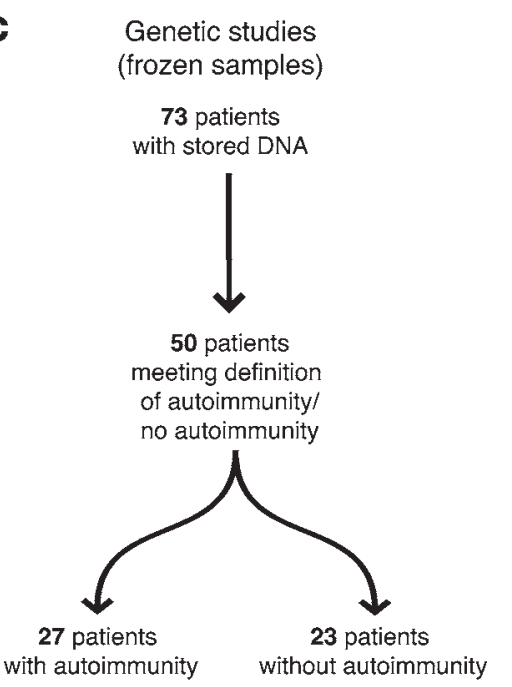

Figure 1

Sample and patient selection. (A) Apoptosis and proliferation were performed on fresh ex vivo samples. Sixty-five patients were studied in total; of these, 29 were studied 9 months after alemtuzumab treatment. Of these, 10 patients met the study criteria for autoimmunity, and 10 patients met the criteria for no autoimmunity. The remaining 9 patients could not be categorized due to transient autoantibody production. (B) Serum IL-21 levels were determined in frozen pretreatment samples from 94 patients. Of these, 59 patients met the criteria for autoimmunity/no autoimmunity, of which, 30 patients had serial ( 3 monthly) samples available (15 with autoimmunity and 15 without autoimmunity). (C) Seventy-three patients gave consent for DNA analysis; of these, 27 patients met the criteria for autoimmunity and 23 patients met the study criteria for no autoimmunity.

reconstitution autoimmunity. Specifically, we show that secondary autoimmunity following alemtuzumab treatment of multiple sclerosis occurs in those patients with greater $\mathrm{T}$ cell apoptosis and cell cycling, driven by genetically determined higher levels of IL-21, detectable even before treatment.

\section{Results}

Alemtuzumab induces a T cell lymphopenia. A single dose of alemtuzumab resulted in the depletion of $\mathrm{CD}^{+}$and $\mathrm{CD}^{+} \mathrm{T}$ lymphocytes to $5.6 \%$ and $6.8 \%$, respectively, of baseline values at month 1 and $30.3 \%$ and $40.8 \%$, respectively, at month 12 (data not shown).

$T$ cells from patients with untreated multiple sclerosis are resistant to cell death. For various assays performed, different cross-sectional and longitudinal samples were used according to availability, as illustrated in Figure 1. As a prelude to measuring lymphocyte cell cycling after alemtuzumab, we examined the proliferative response of $\mathrm{T}$ cells, unstimulated or in culture with myelin basic protein (MBP) or the thyroid-stimulating hormone receptor (TSHr), between untreated patients with multiple sclerosis and normal controls (Figure 2, B and C). There was no difference in proliferation, but survival of $\mathrm{T}$ cells from untreated patients with multiple sclerosis was more than 4-fold greater than that of controls $(P<0.005$; Figure 2D), suggesting that reduced $\mathrm{T}$ cell death is a feature of untreated multiple sclerosis. We confirmed this by dem- onstrating that $\mathrm{T}$ cells from untreated patients are resistant both to passive and Fas-mediated apoptosis compared with healthy controls (passive, $0.3 \%$ vs. $6.7 \%, P=0.0016$; Fas mediated, $2.9 \%$ vs. $15.5 \%, P=0.0018$; Figure $2, \mathrm{~F}$ and $\mathrm{G}$ ).

$T$ cells that regenerate after alemtuzumab are highly proliferative, skewed toward self reactivity, and susceptible to apoptosis. Following alemtuzumab, the proportion of $\mathrm{T}$ cells responding to self antigens (precursor frequency) and the degree of proliferation (proliferative index) were markedly increased compared with untreated patients and healthy controls. For example at month 3, unstimulated $\mathrm{T}$ cell proliferation was increased by more than 6.5 fold compared with untreated patients, and proliferation in response to MBP and TSHr stimulation was increased by $900 \%$ and $700 \%$, respectively (all $P<0.01$; Figure 2, B and C). T cell apoptosis was also markedly increased after alemtuzumab. In response to antigenic stimulation, the proportion of $\mathrm{T}$ cells undergoing apoptosis at 6 months was 10 -fold greater than that at baseline (Figure 2E; $P<0.001$ for all antigens), resulting in fewer viable $\mathrm{T}$ cells at the end of culture (Figure 2D). Passive and Fas-mediated apoptosis were also increased after alemtuzumab, with rates at least double those observed in the healthy control group (passive, $24.5 \%, 22.2 \%$, and $17.9 \%$ at 6,9 , and 12 months, respectively, compared with $6.7 \%$ in controls, all $P<0.001$; Fas mediated, $37.8 \%, 35.8 \%$, and $29.9 \%$ at 6,9 , and 12 months, respectively, compared with $15.5 \%$ in controls, 
A

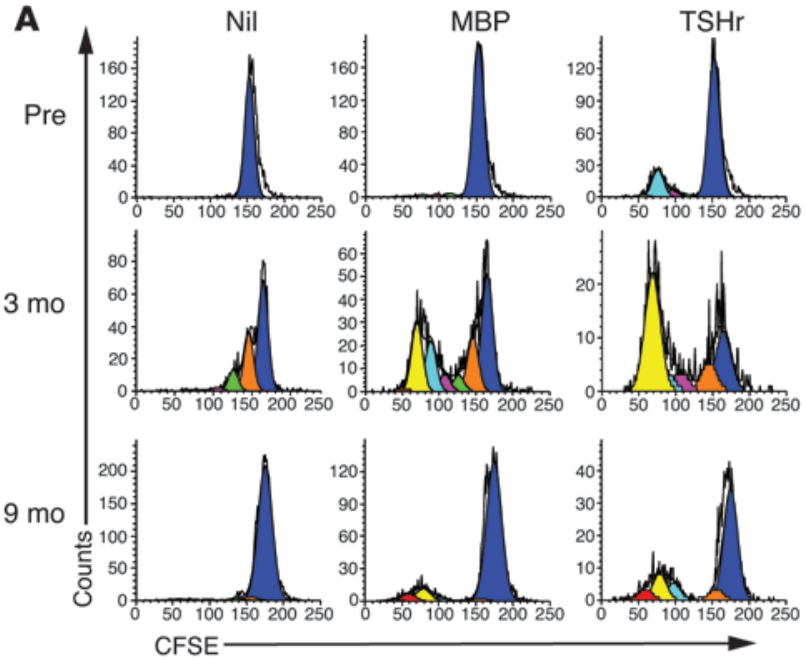

\section{Figure 2}

A cross-sectional study of $T$ cell proliferation and survival following alemtuzumab. (A) Raw CFSE plots are shown, unstimulated (Nil) or following culture with MBP or TSHr. (B and $\mathbf{C}$ ) Precursor frequency and proliferative index of $\mathrm{T}$ cells from healthy controls $(\mathrm{HC})$, untreated patients (Pre), and patients 3, 6, 9, and 12 months after alemtuzumab, unstimulated or following culture with MBP or TSHr. (D) Total number of viable $T$ cells after 10 days in culture. (E) Percentage of $T$ cells apoptosing in response to no stimuli (Unstim) or following culture with MBP and TSHr. (F and $\mathbf{G}$ ) Passive and Fas-mediated T cell apoptosis from healthy controls and patients before and after alemtuzumab (post) (right panels). Representative plots are shown (left panels). (H and I) Passive (Un) and Fas-mediated $\mathrm{CD}^{+}$and $\mathrm{CD}^{+}{ }^{+} \mathrm{T}$ cell apoptosis from healthy controls, pretreatment patients, and at 9 months after alemtuzumab $\left({ }^{*} P<0.05,{ }^{* *} P<0.01,{ }^{* * \star} P<0.001\right)$. Box-and-whisker plots used depict the smallest value, lower quartile, median, upper quartile, and largest value. PI, propidium iodide.

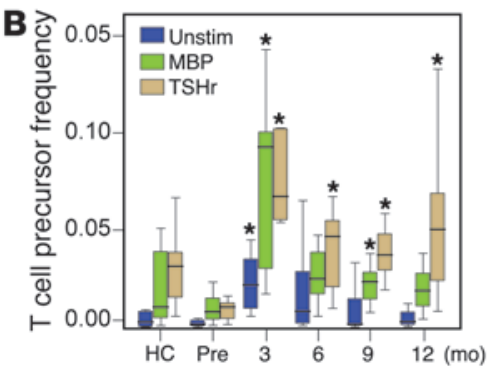

$\mathbf{F}$

Passive
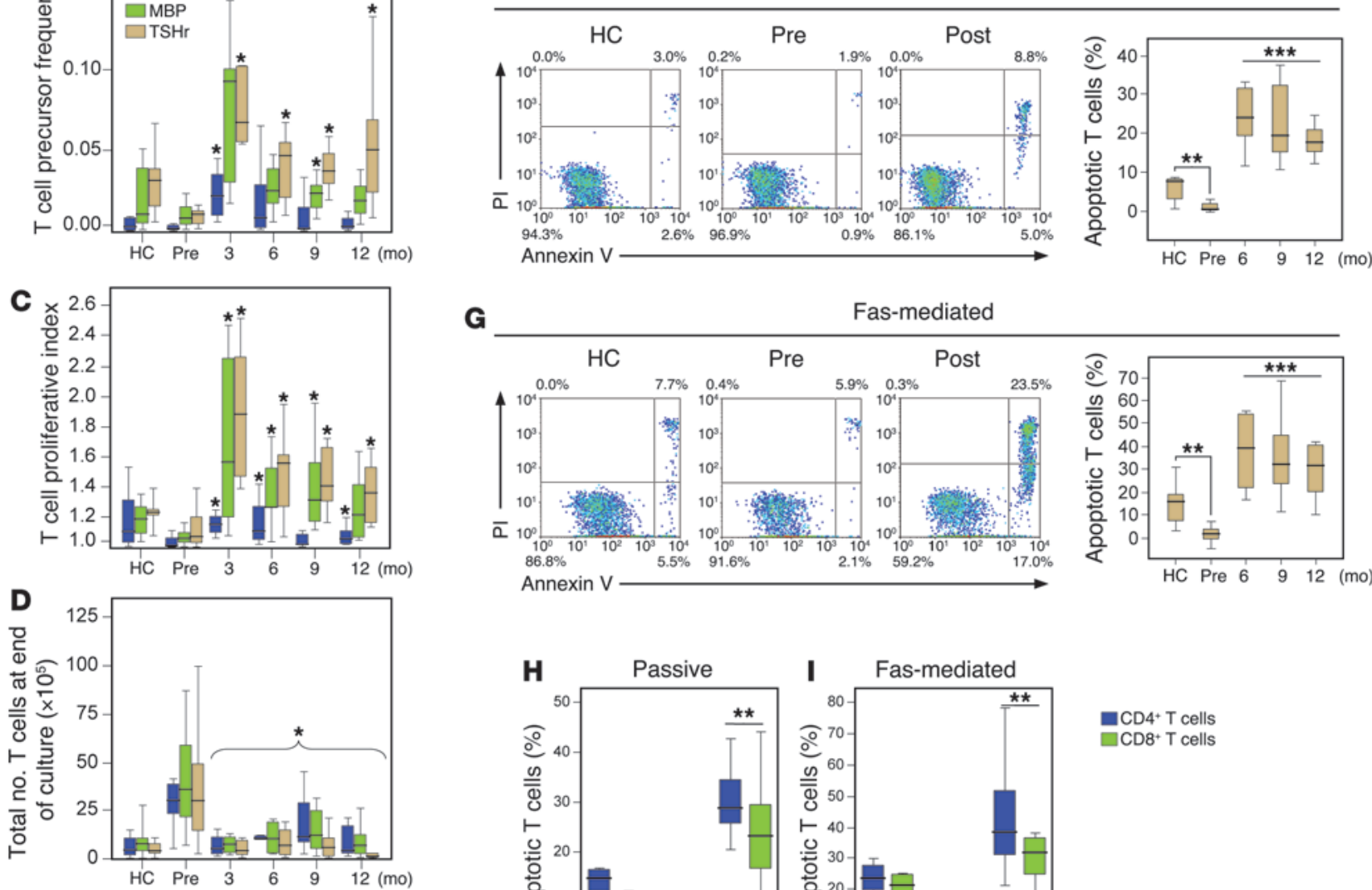

G

Fas-mediated
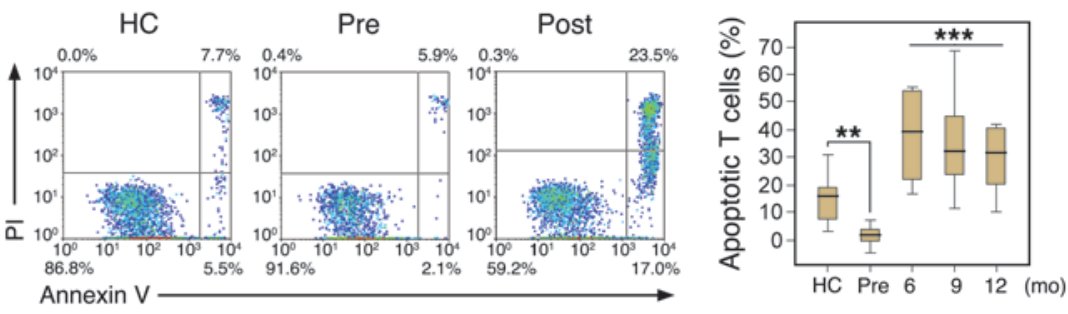

$\mathbf{E}$
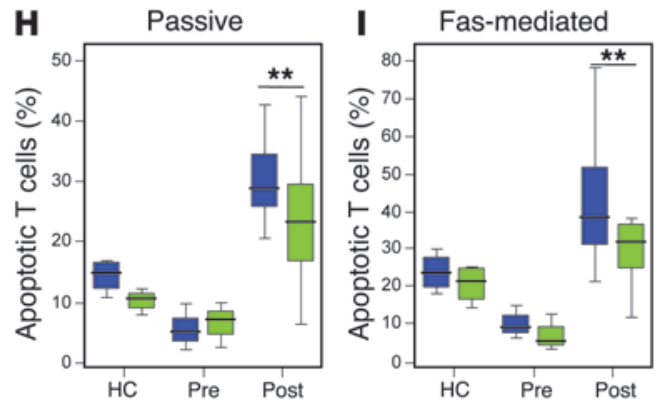

- $\mathrm{CD}^{+} \mathrm{T}$ cells

CD8 $+\mathrm{T}$ cells

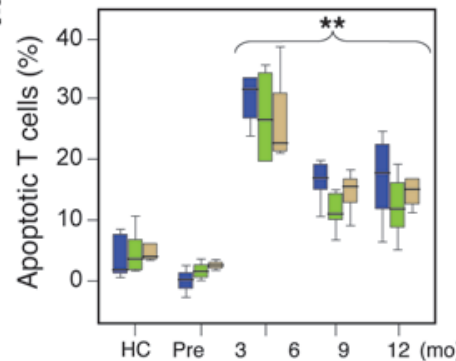


A

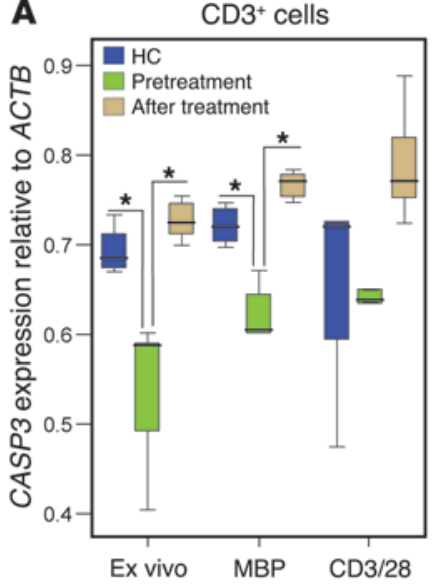

B

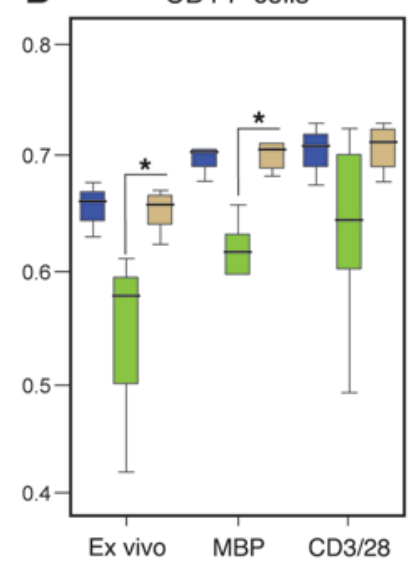

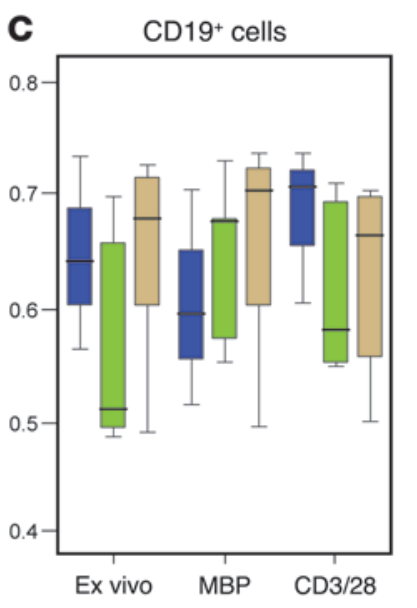

\section{Figure 3}

Caspase-3 expression pretreatment and 9 months after alemtuzumab. CASP3 mRNA expression relative to $A C T B$ mRNA expression in $(\mathbf{A}) \mathrm{CD}^{+} \mathrm{T}$ cells, (B) CD14+ monocytes, and (C) CD19+ B cells, either immediately ex vivo or following stimulation with MBP or polyclonal stimulation (anti-CD3/28 antibodies) $\left({ }^{*} P<0.05\right)$. Box-and-whisker plots used depict the smallest value, lower quartile, median, upper quartile, and largest value. all $P<0.01$; Figure 2, F and G). Increased lymphocyte apoptosis after alemtuzumab was seen in both the $\mathrm{CD}^{+}$and $\mathrm{CD}^{+}$subpopulations (Figure 2, H and I) and persisted for at least 18 months after alemtuzumab treatment (data not shown).

$T$ cells from untreated patients with multiple sclerosis underexpress caspase-3. To substantiate these observations on apoptosis, we measured $\mathrm{T}$ cell mRNA expression of caspase-3 (CASP3), the effector caspase common to both apoptotic pathways. This was reduced in untreated multiple sclerosis patients compared with controls; this was significant for unstimulated and MBP-stimulated PBMCs (by $78 \%$ and $87 \%$, respectively, both $P<0.05$, after correction for multiple comparisons) but not for polyclonal-stimulated cultures (Figure 3A). A similar trend was seen in $\mathrm{CD} 14^{+}$cells (but not CD19+ cells), although this difference did not survive correction for multiple comparisons (Figure 3B). After alemtuzumab, caspase-3 expression was significantly increased in $\mathrm{T}$ cells and monocytes, reaching levels seen in healthy controls $(P<0.05$; Figure 3 , A and
B). Expression of all other genes tested (listed in Methods) was unchanged after alemtuzumab.

Secondary autoimmunity after alemtuzumab is associated with excessive Tcell apoptosis. Having demonstrated increased lymphocyte proliferation and apoptosis as a generic response to treatment, we tested the relationship between $\mathrm{T}$ cell apoptosis and development of autoimmunity after alemtuzumab, defined as development of a novel autoimmune disease and/or persistent autoantibodies above the normal range, after alemtuzumab, sustained over at least 3 months.

Using this definition, $T$ cells derived from patients with autoimmunity $(n=10)$ showed significantly higher levels of apoptotic cell death in all culture conditions at 9 months after treatment, when compared with $\mathrm{T}$ cells from nonautoimmune patients $(n=10)$ studied at the same time point (unstimulated, $4.7 \%$ vs. $14.4 \%$; Fas mediated, $18.2 \%$ vs. $32.1 \%$; MBP, $7.6 \%$ vs. $17.6 \%$; $\mathrm{TSHr}$, $9.5 \%$ vs. $25.5 \% ; P<0.01$ for all comparisons; Figure 4). If a stricter definition of autoimmunity is applied, that being development of
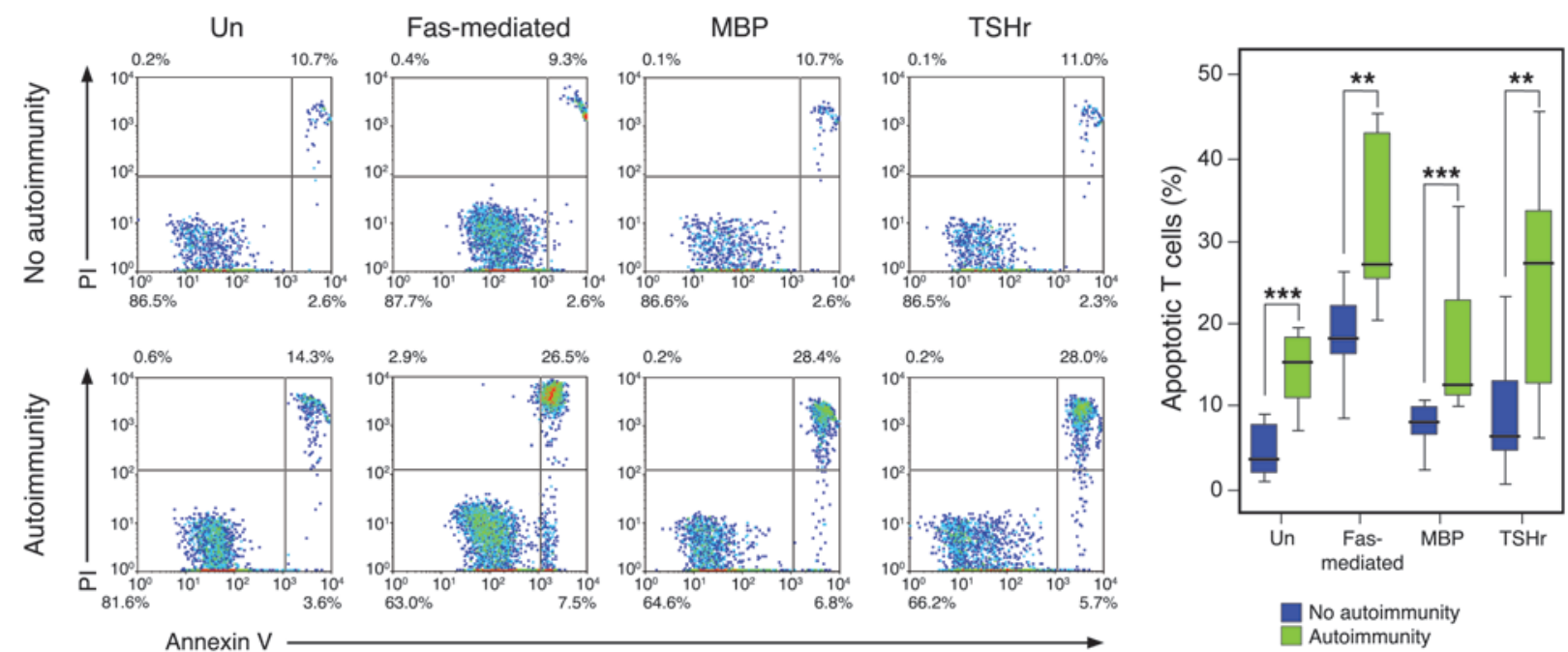

Figure 4

Autoimmunity after alemtuzumab is associated with excessive T cell apoptosis. Percentage of T cell apoptosis 9 months after alemtuzumab: passive, Fas-mediated, and in response to MBP and TSHr stimulation in those without autoimmunity $(n=10)$ and those with secondary autoimmunity $(n=10)\left({ }^{\star \star} P<0.01,{ }^{\star * \star} P<0.001\right)$. Representative plots are shown. Box-and-whisker plots used depict the smallest value, lower quartile, median, upper quartile, and largest value. 

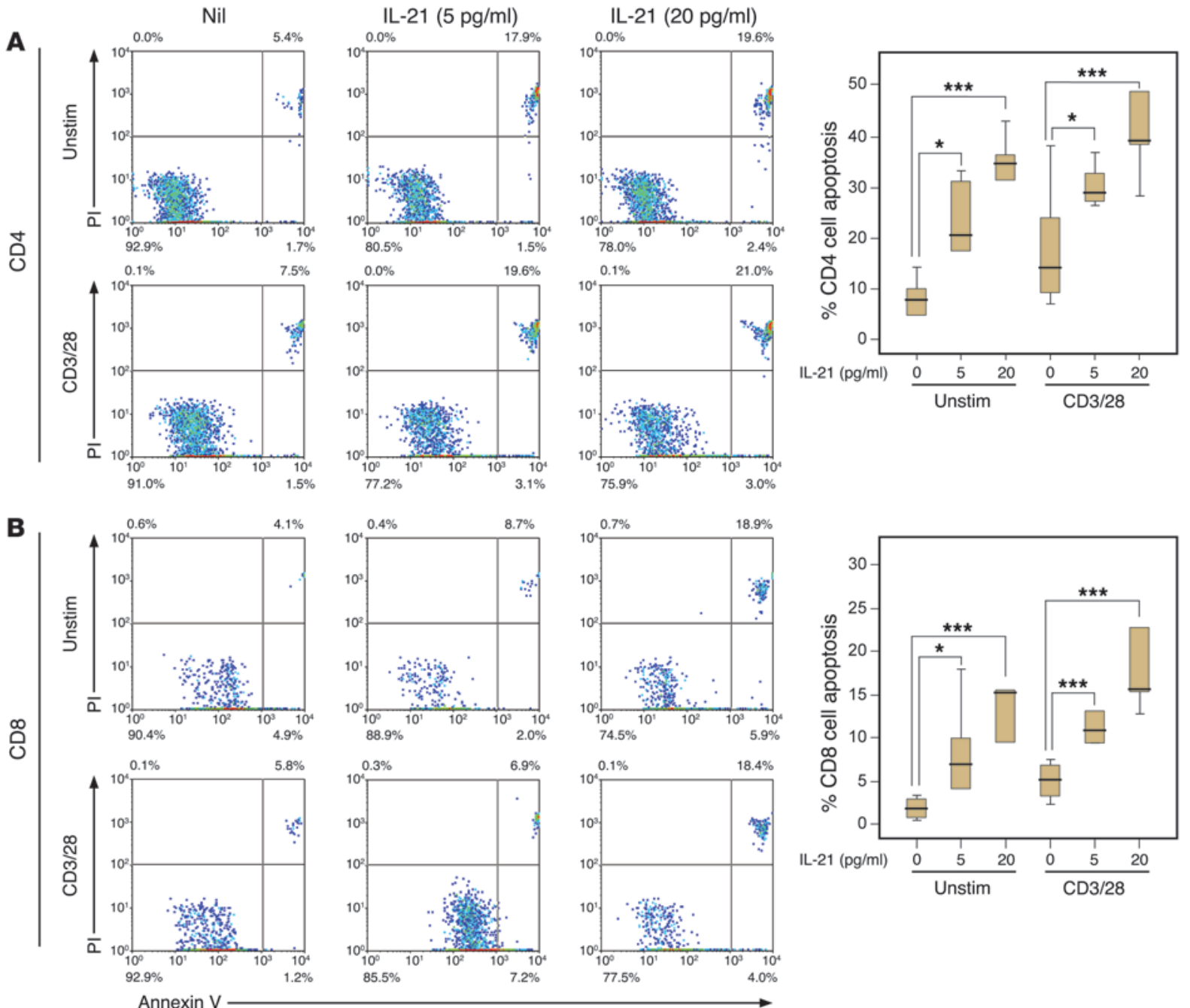

Figure 5

rhlL-21 induces T cell apoptosis in vitro. (A) CD4+ T cells and (B) CD8 ${ }^{+} \mathrm{T}$ cells, unstimulated or polyclonally stimulated (anti-CD3/CD28), apoptose in response to rhlL-21 in a dose-dependent manner. ( ${ }^{\star} P<0.05,{ }^{* * \star} P<0.001$ ). Representative plots are shown (left panels). Box-and-whisker plots used depict the smallest value, lower quartile, median, upper quartile, and largest value.

an autoimmune disease, excluding nonpathogenic antibody production, the difference remains, despite reducing the number in the autoimmune group to 7 (unstimulated, 4.7\% vs. 15.4\%; Fas mediated, $18.2 \%$ vs. $31.7 \%$; MBP, $7.6 \%$ vs. $20.2 \%$; TSHr, $9.5 \%$ vs. $13.4 \%$; $P<0.02$ for all comparisons).

Both groups are markedly $\mathrm{T}$ cell depleted, with no difference in the rate of $\mathrm{T}$ cell reconstitution (e.g., at 6 months, CD4 counts are $0.15 \times 10^{9} / 1$ vs. $0.19 \times 10^{9} / 1$ and CD 8 counts are $0.11 \times 10^{9} / 1$ vs. $0.11 \times 10^{9} / 1$ in those with and without autoimmunity, respectively; data not shown). Therefore, the autoimmune group is characterized by higher rates of proliferation and apoptosis but no net difference in lymphocyte numbers; in other words, it is characterized by increased $\mathrm{T}$ cell cycling.

IL-21 induces T cell proliferation and apoptosis and is associated with the development of secondary autoimmunity after alemtuzumab. The NOD mice data would suggest that this increased cell cycling is driven by high levels of IL-21; therefore, we tested the effect of exogenous IL-21 on apoptosis and proliferation of human
T cells in vitro. Spiking PBMCs from healthy controls with recombinant human IL-21 (rhIL-21) led to an increase in the apoptotic death of unstimulated and polyclonally stimulated $\mathrm{CD}^{+}$(Figure $5 \mathrm{~A})$ and $\mathrm{CD}^{+}$(Figure 5B) $\mathrm{T}$ cells in a dose-dependent manner $(P<0.05$ for all conditions). Spiking unstimulated cells with rhIL-21 led to a small but significant increase in the proliferation of both $\mathrm{CD}^{+}$and $\mathrm{CD}^{+} \mathrm{T}$ cells, with an increase both in proliferative index $\left(\mathrm{CD}^{+}, 1.07\right.$ vs. $1.25, P=0.017 ; \mathrm{CD}^{+}, 1.09$ vs. 1.32 , $P=0.017$; Figure $6 \mathrm{~B})$ and precursor frequency $\left(\mathrm{CD} 4^{+}, 0.007 \mathrm{vs}\right.$. $0.014, P=0.016$; $\mathrm{CD}^{+}, 0.007$ vs. $0.015, P=0.026$; Figure $\left.6 \mathrm{D}\right)$. IL-21 did not affect the proportion of $\mathrm{CD}^{+}$or $\mathrm{CD}^{+} \mathrm{T}$ cells proliferating in response to polyclonal stimulation (Figure 6E), suggesting they were already maximally stimulated. However, IL-21 led to a significant increase in the extent of $\mathrm{CD}^{+}$cell proliferation (proliferative index, 11.59 vs. $19.39, P=0.012$; Figure $6 \mathrm{C}$ ).

Next, we determined serum IL-21 levels in all patients with stored serial samples $(n=30 ; 15$ with autoimmunity and 15 with no autoimmunity after alemtuzumab; Figure 1B). Those with 
A
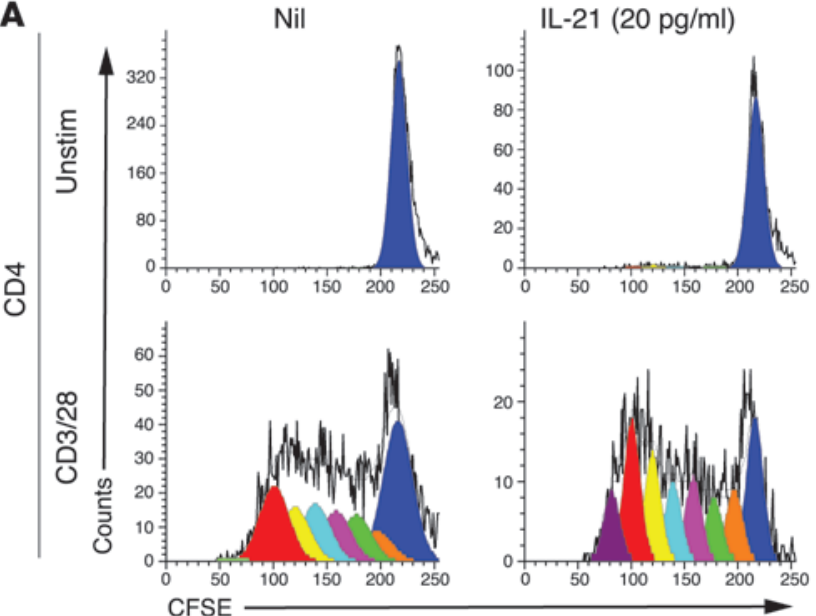

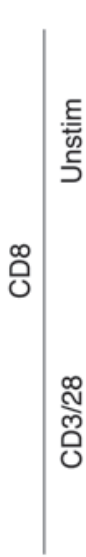
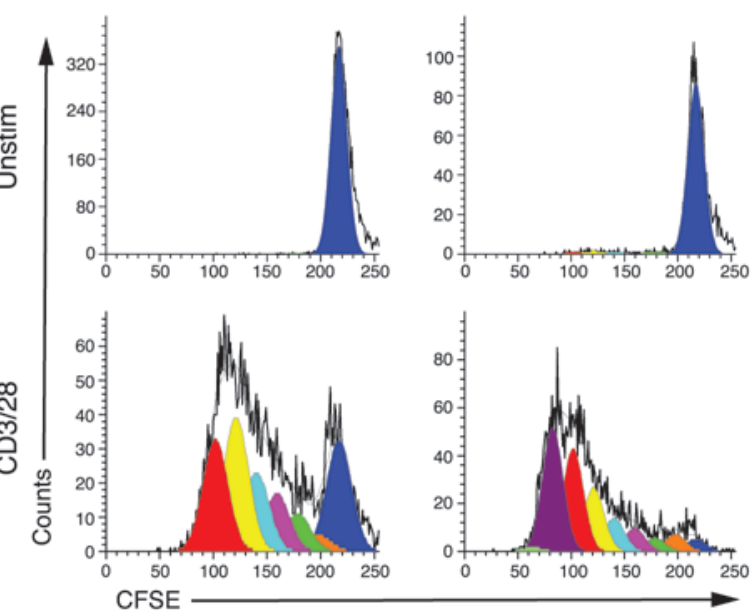
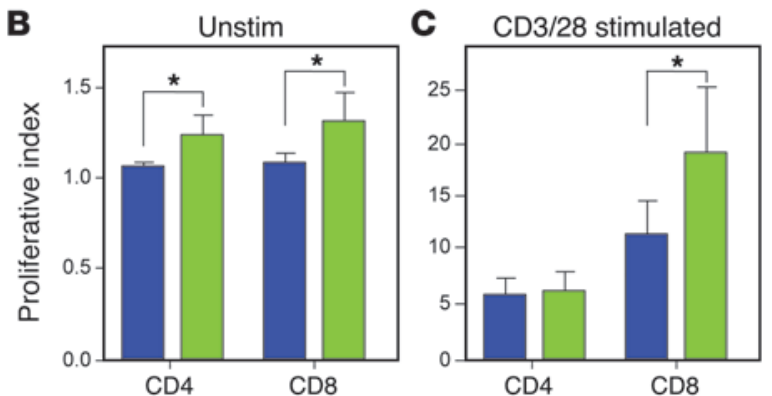

D
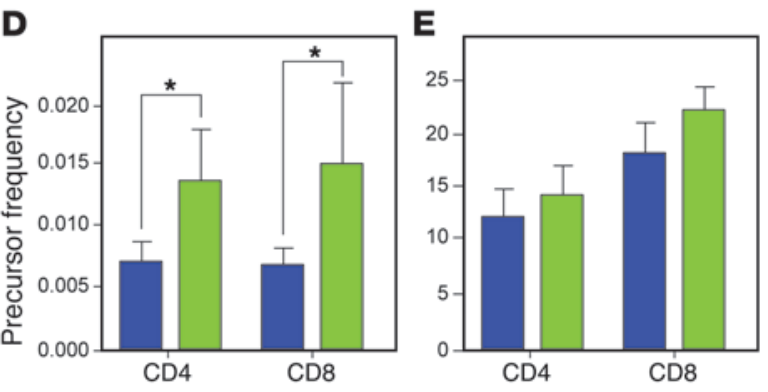

$-\mathrm{IL}-21(20 \mathrm{pg} / \mathrm{ml})$
$+\mathrm{IL}-21(20 \mathrm{pg} / \mathrm{ml})$

\section{Figure 6}

rhIL-21 induces T cell proliferation in vitro. (A) Representative CFSE plots showing unstimulated and polyclonally stimulated (CD3/28) CD4+ T cells and $\mathrm{CD}^{+} \mathrm{T}$ cells with and without rhIL-21. (B and $\left.\mathbf{C}\right)$ The proliferative index of unstimulated and polyclonally stimulated (anti-CD3/CD28) $\mathrm{CD}^{+}$and $\mathrm{CD} 8^{+} \mathrm{T}$ cells in response to rhIL-21. (D and E) Precursor frequency of unstimulated and polyclonally stimulated $\mathrm{CD} 4^{+}$and $\mathrm{CD} 8^{+} \mathrm{T}$ cells in response to rhIL-21 $\left({ }^{*} P<0.05\right)$. Errors bars indicate $1 \mathrm{SD}$.

autoimmunity were found to have more than 2 -fold higher serum IL-21 levels at all time points after alemtuzumab, compared with those without autoimmunity (mean values for month $1,133.5 \mathrm{pg} /$ $\mathrm{ml}$ vs. $426 \mathrm{pg} / \mathrm{ml}, P=0.01$; month $3,119.4 \mathrm{pg} / \mathrm{ml}$ vs. $480.5 \mathrm{pg} / \mathrm{ml}$, $P=0.008$; month 6, $173.9 \mathrm{pg} / \mathrm{ml}$ vs. $456.4 \mathrm{pg} / \mathrm{ml}, P=0.04$; month $12,186.7 \mathrm{pg} / \mathrm{ml}$ vs. $424.5 \mathrm{pg} / \mathrm{ml}, P=0.02)$. This difference was also evident before treatment (mean values, $192.5 \mathrm{pg} / \mathrm{ml}$ vs. 505.6 $\mathrm{pg} / \mathrm{ml}, P=0.016$; Figure $7 \mathrm{~A}$ ). When the analysis was extended to include all patients with available pretreatment serum (32 patients with autoimmunity, 27 patients without autoimmunity; Figure 1B), the difference remained, with those developing autoimmunity having more than 2 -fold higher serum IL-21 levels than the nonautoimmune group (mean values, $206 \mathrm{pg} / \mathrm{ml} \mathrm{vs.} 430 \mathrm{pg} / \mathrm{ml}$, $P=0.001)$. Furthermore, serum IL-21 levels from untreated patients with multiple sclerosis $(n=59)$ were found to be greater than controls $(n=19)(327 \mathrm{pg} / \mathrm{ml}$ vs. $213 \mathrm{pg} / \mathrm{ml}, P=0.041)$; however, this was entirely accounted for by high IL-21 levels in those patients who went on to develop secondary autoimmunity (Figure 7B). To illustrate how this test might be used clinically, we tested the hypothesis that pretreatment serum IL-21 levels above an arbitrary threshold of $210 \mathrm{pg} / \mathrm{ml}$ predicted autoimmunity after alemtuzumab. When applied to the pretreatment samples $(n=59)$, 21 of 30 were true positives and 11 of 29 were true negatives, representing a sensitivity of $66 \%$ and specificity of $67 \%$, with a positive predictive value of $70 \%$ and negative predictive value of $62 \%$.

IL-21 genotype influences IL-21 expression and associates with autoimmunity. We wanted to know whether serum IL-21 heterogeneity was driven by IL-21 genetic polymorphisms. So, in a pilot study, we approached all our of local alemtuzumab patients for DNA testing. We genotyped all 73 subjects, in whom serum IL-21 concentration before alemtuzumab treatment had been determined, for 4 SNPs that lie within a block of linkage disequilibrium (LD) on chromosome 4q27, encoding the IL21 gene. The minor allele frequency for all 4 SNPs was in line with published data: rs13151961G (14.5\%), rs6822844T (14.6\%), rs4833837G (38.0\%), and rs6840978T (18.1\%) (19). We found that the genotype at 3 of the 4 SNPs (rs13151961 $\mathrm{A} / \mathrm{A}, \mathrm{rs} 6822844 \mathrm{G} / \mathrm{G}$, and $\mathrm{rs} 6840978 \mathrm{C} / \mathrm{C}$ ) was associated with significantly higher levels of serum IL-21 $(P=0.0076, P=0.0098$, and $P=0.0067$, respectively). The genotype at rs 4833837 did not influence IL-21 production. The LD between rs4833837 and the 3 other 


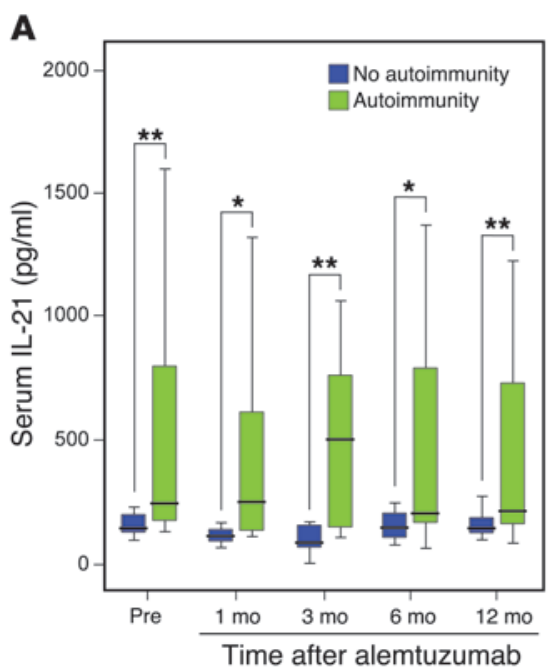

B

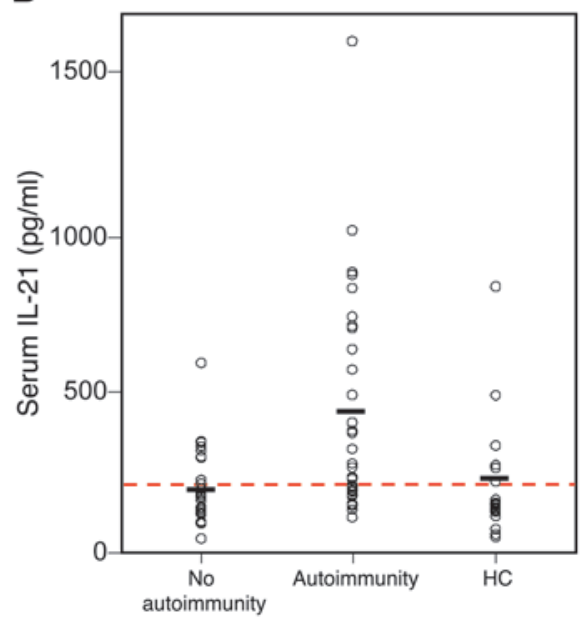

\section{Figure 7}

Serum IL-21. (A) Serial serum IL-21, prior to, and after alemtuzumab treatment, in 15 patients with autoimmunity and in 15 patients without secondary autoimmunity. (B) Pretreatment serum IL-21 levels in the nonautoimmune $(n=27)$ and autoimmune $(n=32)$ cohorts compared with healthy controls $(n=19)$. The red dotted line represents serum IL-21 level of $210 \mathrm{pg} / \mathrm{ml}$ and the black horizontal lines represent mean values for each group (nonautoimmune, $206 \mathrm{pg} / \mathrm{ml}$; autoimmune, $430 \mathrm{pg} / \mathrm{ml}$; and healthy controls, $213 \mathrm{pg} / \mathrm{ml})\left({ }^{*} P<0.05\right.$, $\left.{ }^{* *} P<0.01\right)$. Box-and-whisker plots used depict the smallest value, lower quartile, median, upper quartile, and largest value.
SNPs is low $\left(\mathrm{r}^{2}<0.15\right)$, therefore, a SNP which lies on the haplotype rs13151961(A)-rs6822844(G)-rs6840978(C) is most likely to be associated with increased IL-21 production. The genotype frequencies for $H L A-D R B 1 * 1501$, rs2104286 (IL2RA), and rs6897932 $(I L 7 R)$ did not differ from published data for other unselected patients with multiple sclerosis $(20,21)$.

Finally, in order to address whether genotype influences susceptibility to autoimmunity after alemtuzumab, we categorized as many patients as possible into those who did (27 subjects) and definitely did not (23 subjects) develop autoimmunity after alemtuzumab. Twenty-three patients could not be categorized due to transient autoantibody production. The genotypes (rs13151961 A/A, rs6822844 $\mathrm{G} / \mathrm{G}$, rs6840978 C/C) shown to be associated with higher serum IL-21 concentration tended to associate nonsignificantly with autoimmunity after alemtuzumab. For the rs 13151961 allele, 19 of 31 (61.3\%) of those with the at risk allele (A/A) developed autoimmunity versus 7 of $16(43.8 \%)$ without the at-risk allele $(P=0.25)$. Similar values were obtained for the other at-risk alleles. Despite studying all possible samples, we recognize that our numbers remain very small for a study of genetic risk factors, and therefore, the observed lack of statistical significance was not unexpected.

\section{Discussion}

Here, we have studied one example of human lymphopenia-associated autoimmunity, arising after alemtuzumab treatment of multiple sclerosis. We showed that autoimmunity arises in those patients with greater $\mathrm{T}$ cell apoptosis and cell cycling, driven by genetically determined higher levels of IL-21, detectable even before treatment. We propose that, by driving cycles of $\mathrm{T}$ cell expansion and death to excess, IL-21 increases the probability of generating self-reactive $T$ cells and, hence, for autoimmunity.

We first described autoimmunity complicating alemtuzumab (Campath-1H) treatment in 1999 (3) and have continued to observe this complication of what is increasingly recognized as a highly effective therapy for early relapsing-remitting multiple sclerosis (1-3). The present study, involving a series of small cohorts of available patients, was aimed at understanding this unprecedented "model" of human autoimmunity.

The association between induced lymphopenia and autoimmunity is well recognized. Under lymphopenic conditions, the remaining $\mathrm{T}$ cells undergo extensive compensatory expansion in order to reconstitute the immune system. This process, termed homeostatic proliferation, relies on stimulation through the TCRself peptide-MHC complex (22-24) and so results in a population skewed toward increased recognition of self antigen, as seen in this study. In addition, rapidly expanding $T$ cells acquire the phenotype and functional characteristics of memory cells, including reduced dependence on costimulation, the ability to respond to lower doses of antigen than naive cells, and the rapid secretion of inflammatory cytokines on restimulation, so further promoting the breakdown of self tolerance (25-28). Yet, despite these changes, autoimmunity is not an inevitable consequence of lymphopenia. Indeed, as with our patients, most lymphopenic subjects do not develop autoimmunity, suggesting that additional "cofactors" are required. We have already disproved the suggestion that those who develop autoimmunity have selective depletion of Tregs (15). Another possibility arises from the demonstration that excessive cell cycling and reduced T cell survival, driven by the overproduction of IL-21, underlie the development of diabetes in the NOD mouse (14). Here, we demonstrate for what we believe to be the first time in humans that overproduction of IL-21 is also the "second hit" required in the development of secondary autoimmunity, following otherwise successful treatment of multiple sclerosis with alemtuzumab.

In line with previous reports (29-32), we showed that $\mathrm{T}$ cells from people with untreated multiple sclerosis are resistant to apoptosis. Now, we added evidence that this resistance is associated with underexpression of caspase-3. Consistent with the position of this effector caspase at the convergence point of the extrinsic and intrinsic apoptotic pathways, we have demonstrated $\mathrm{T}$ cell resistance both to Fas-mediated and passive apoptosis in our patients. Underexpression of caspase- 3 has been described in a number of other autoimmune diseases, including type 1 diabetes (33), Hashimoto thyroiditis, and autoimmune polyendocrine syndrome-2 (34). We believe this is, however, a novel finding in multiple sclerosis.

The immune state is radically altered following exposure to alemtuzumab. As predicted, T cells regenerating into the lymphopenic environment generated by alemtuzumab are highly proliferative and skewed toward autoreactivity. However, less intuitively but in keeping with observations in the NOD mouse (14), these cells are highly unstable and short lived. While their fate has not 
previously been directly addressed (14), we show that these cells are dying rapidly by apoptosis. High and sustained levels of T cell apoptosis may explain why a single dose of alemtuzumab induces $\mathrm{T}$ cell lymphopenia lasting several years, even though the half-life of circulating alemtuzumab is only 6 days, and hematological precursors are not depleted (35).

Against that background, we showed that patients with secondary autoimmunity have higher rates of $\mathrm{T}$ cell apoptosis, but no greater $T$ cell lymphopenia, than those without autoimmunity, suggesting increased cell cycling in this group. These perturbations of $\mathrm{T}$ cell cycling were associated with higher serum IL-21 expression and, in vitro IL-21 was shown to promote both the proliferation and apoptosis of human $\mathrm{CD}^{+}$and $\mathrm{CD}^{+} \mathrm{T}$ cells. Furthermore, susceptibility to lymphopenia-associated autoimmunity was manifest before lymphodepletion, with pretreatment IL-21 levels predicting with some accuracy (positive predictive value of $70 \%$ and negative predictive value of $62 \%$ ) the development of autoimmunity months to years after exposure to alemtuzumab. This has major implications for selecting and managing patients with multiple sclerosis, when considering lymphocyte-depleting therapy with alemtuzumab. IL-21 may promote autoimmunity by various mechanisms, including inducing proinflammatory Th17 cells (36), promoting B cell differentiation and antibody production $(37,38)$, or by reducing the suppressor effect of Tregs $(39,40)$; although other data suggest that IL-21 may, in fact, promote Treg function (41). Our position is that by driving cycles of T cell expansion and death to excess, IL-21 increases the stochastic opportunities for $\mathrm{T}$ cells to encounter self antigen and break tolerance, hence promoting autoimmunity. This may account for the association of a locus on chromosome 4q27, close to the IL2 and IL21 genes, with psoriasis (42), celiac disease (43), type 1 diabetes (44), and rheumatoid arthritis (45). Despite small patient numbers, we have demonstrated that IL-21 production is genetically determined. Furthermore, in keeping with our hypotheses, the genotype associated with high IL-21 production appears to be a risk factor for the development of secondary autoimmunity after alemtuzumab.

The preponderance of thyroid disease and autoimmune cytopenias seen in our patients and in other examples of reconstitution autoimmunity (4-8) is intriguing and is not fully explained. We have previously shown that the risk of developing Graves disease after alemtuzumab is not associated with a particular HLA type or TNF- $\alpha$ or IL-10 promoter polymorphism (3). Furthermore, in the CAMMS-223 study, there was no relationship between secondary autoimmunity after alemtuzumab and multiple sclerosis disease activity (Alasdair J. Coles, personal communication). It remains to be explained, therefore, how alemtuzumab switches off one autoimmune disease, i.e., multiple sclerosis, while rendering patients susceptible to novel autoimmunity. One possibility is that the profile of autoimmunity arising out of lymphopenia reflects the likelihood of a given $\mathrm{T}$ cell meeting its cognate antigen. Perhaps, by virtue of the blood brain barrier, antigens expressed within the central nervous system are less "available" to the immune system and are therefore less likely to drive homeostatic reconstitution. An alternative suggestion is that multiple sclerosis disease activity, unlike ITP and Graves disease, is not driven by IL- 21 .

In summary, our data provided the first exploration of lymphopenia-induced autoimmunity to our knowledge in humans, building on and expanding previous experimental studies. They provided a conceptual framework for understanding lymphopenia-associated autoimmunity that goes beyond the narrow context of treating multiple sclerosis with alemtuzumab, which is now in phase III trials. The concept is that, first, therapeutic lymphocyte depletion and, second, genetically restricted overproduction of IL-21 leads to a state of excess T cell cycling and reduced survival, which promotes autoimmunity in humans.

\section{Methods}

Subjects. All patients had relapsing-remitting multiple sclerosis and were participants in 1 of 2 clinical trials, CAMMS-223 and CAMMS-224 (Cambridge UK Research Ethics Committee [REC 02/315 and 03/078]), in which alemtuzumab (supplied by Genzyme) is given by intravenous infusion of $12-24 \mathrm{mg} / \mathrm{d}$ for 5 days, followed by retreatment at 12 months. Patients and controls consented to venesection for research purposes (studies were approved by Cambridge UK Research Ethics Committee [LREC 02/263]) and all were free from exposure to other disease-modifying agents, including steroids, for at least 1 month at the time of blood sampling. For each experiment, all available samples, from all relevant patients, at all possible time points were used; there was no subgroup selection. More samples were available for serum studies, as retrospective frozen samples could be used. Assays of lymphocyte biology could not be performed on many patients shortly after alemtuzumab due to their profound lymphopenia. All DNA samples were collected with informed written consent and approval of Thames Valley Multi-centre Research Ethics Committee (06/MRE12/11).

Lymphocyte proliferation and apoptosis data were generated by a crosssectional study of fresh, ex vivo cells from 65 patients and 21 healthy controls (7 males; mean age, 34 years) (Figure 1A). This generated hypotheses about $\mathrm{T}$ cell cycling in the pathogenesis of secondary autoimmunity, which were tested on samples available at 9 months after alemtuzumab treatment, which was chosen as the earliest time point in which $\mathrm{T}$ cell apoptosis can be robustly analyzed. Of the 29 samples available at this time point, 10 met our study definition of autoimmunity ( 1 male; mean age, 36 years), and 10 met our definition of no autoimmunity ( 3 males; mean age, 38 years). Autoimmunity was defined as the development of a novel autoimmune disease (with or without autoantibodies) or persistent autoantibodies above the normal range (present on at least 2 occasions at least 3 months apart), without clinical disease. No autoimmunity was defined as the absence of an autoimmune disease and autoantibodies for at least 18 months after alemtuzumab. Of the 10 patients with autoimmunity, 3 had autoantibodies only (antinuclear antibodies).

Pretreatment serum IL-21 was available on 94 patients (Figure 1B). Of these, 27 met the definition of no autoimmunity, and 32 had secondary autoimmunity after alemtuzumab ( 8 with autoantibodies only and 6 with antinuclear and 2 with anti-smooth muscle antibodies; 21 with thyroid autoimmunity, 2 with ITP, and 1 with Goodpasture disease). The remaining 35 subjects could not be categorized because they produced an autoantibody after alemtuzumab transiently. Of the 59 patients who could be categorized, serial sera (at 3 monthly intervals after alemtuzumab) were available for 30 patients: 15 with autoimmunity ( 3 males; mean age, 34 years; 12 with thyroid autoimmunity, 1 with Goodpasture, 1 with ITP, and 1 with antinuclear antibodies only) and 15 without autoimmunity (5 males; mean age, 31 years). Controls were 19 healthy subjects ( 7 males; mean age, 33 years).

To determine whether serum IL-21 heterogeneity is driven by IL-21 genetic polymorphisms, all subjects with stored DNA were studied $(n=73)$ (Figure 1C). To determine whether genotype influences susceptibility to autoimmunity after alemtuzumab, all 50 subjects who met the definition of autoimmunity/no autoimmunity were studied. Of these, 23 had no autoimmunity and 27 had secondary autoimmunity after alemtuzumab (6 with autoantibodies only, 4 with antinuclear and 2 with anti-smooth 
muscle antibodies; 18 with thyroid autoimmunity, 2 with ITP, and 1 with Goodpasture disease).

Peripheral mononuclear cell cultures. PBMCs were isolated from heparinized blood by centrifugation on a Ficoll-Paque density gradient (Amersham Pharmacia Biotech). Whole PBMCs were immediately suspended in culture medium (RPMI), containing 1\% penicillin, 1\% streptomycin, and 10\% fetal calf serum (S5394; Sigma-Aldrich), and adjusted to a concentration of $10^{6} / \mathrm{ml}$ viable cells (determined by trypan blue exclusion). To induce passive cell death, PBMCs were incubated for 72 hours in media alone without additional growth factors. Fas-mediated apoptosis was induced by culturing PBMCs for 48 hours with soluble anti-CD28 $(1 \mu \mathrm{g} / \mathrm{ml}$; donated by M. Frewin, University of Oxford, Oxford, United Kingdom) in antiCD3 monoclonal antibody-precoated plates $(1 \mu \mathrm{g} / \mathrm{ml}$; BD Biosciences Pharmingen), followed by 18 hours incubation with activating anti-human Fas (clone CH11, 1 rg/ml; Upstate Biotechnology).

Detection of apoptosis. Apoptotic T cells were detected by staining cells with allophycocyanin-conjugated mouse anti-human monoclonal antibodies against CD3 (MCA463APC; Serotec), CD4 (MCA1267APC; Serotec), and CD8 (MCA1226APC; Serotec) and FITC-conjugated annexin-V and propidium iodide (BD Biosciences - Pharmingen). Fluorescence was detected by flow cytometry (FACScalibur; Becton Dickinson). Based on forward and side scatter, a wide lymphocyte gate was drawn to include live and apoptotic lymphocytes (having reduced forward scatter and increased side scatter). At least 15,000 events within the gate were collected and analyzed using WinMDI 2.8 software. Early apoptotic cells were defined as annexin- $\mathrm{V}^{+}$ propidium iodide $\left(\right.$ annexin $\left.\mathrm{V}^{+} \mathrm{PI}^{-}\right)$, and late apoptotic or necrotic cells were defined as annexinV $\mathrm{V}^{+} \mathrm{PI}^{+}(46)$. Apoptotic cell death was defined as total cell death $\left(\right.$ annexin $V^{+} \mathrm{PI}^{-}$plus annexin $\left.\mathrm{V}^{+} \mathrm{PI}^{+}\right)$blocked by pan-caspase inhibition with General Caspase Inhibitor Q-VD-OPh (OPH001; R\&D Systems).

Proliferation assays. $\mathrm{PBMCs}$ were loaded with the cell division tracking dye CFSE (47) and cultured with $50 \mu \mathrm{g} / \mathrm{ml} \mathrm{MBP}$ (Research Diagnostics Inc.) or $1 \mu \mathrm{g} / \mathrm{ml}$ TSHr extracellular domain bound to a matrix binding protein (donated by M. Ludgate, Cardiff University, Cardiff, United Kingdom). After 10 days, CFSE staining in cells, identified by specific surface markers (CD4, CD8), was analyzed by flow cytometry. Precursor frequency (defined as the proportion of lymphocytes that left the parent population to undergo at least 2 cell divisions) and proliferation index (defined as the sum of the cells in all generations divided by the computed number of parent cells) were calculated using Modfit LT 3.0 (Verity Software). The absolute number of surviving cells was measured by comparison with a fixed number of inert beads (BD Calibrite; BD Biosciences) included in cultures.

$m R N A$ analysis. PBMCs, immediately ex vivo or after culture with $\mathrm{MBP}$ or polyclonal stimulation, were positively separated, using $20 \mu \mathrm{l}$ of magnetic beads (CD19 Microbeads, CD3 Microbeads, CD14 Microbeads; Miltenyi Biotec) per $1 \times 10^{7}$ cells loaded into a MACS LS Column. Magnetically retained cells were eluted, washed, and stored in RNAlater (Ambion) at $-70^{\circ} \mathrm{C}$ (cell purity was consistently $95 \%-98 \%$; data not shown).

Fas, FasL, Bcl-2, Bcl-Xl, Bad, Bax, Bid, Bim, Survivin, c-FLIP, and caspase-3, -8 , and -9 expression was determined by semiquantitative RT-PCR. mRNA was extracted from cells stored in RNAlater using the RNeasy Mini Kit (Qiagen) and reverse transcribed to cDNA using the Pro-STAR First-Strand RT-PCR Kit (Stratagene). PCR primers and probes were designed using Primer Express (PE Biosystems) and purchased from Oswel DNA service. mRNA sequence information was obtained from Genbank. Quantitative real-time PCR was performed on an ABI Prism 7900HT Sequence Detection System (PerkinElmer), using PCR MasterMix containing ROX (RT-QP2X-03; Eurogentec). Primer and probe sequences were as follows: Bcl-2, forward, 5'-CCTGTGGATGACTGAGTACCTGAA-3', reverse, 5'CACCTACCCAGCCTCCGTTA-3'; JOE-labelled probe, 5'-CGGCACCTGCACACCTGGATC-3'; Bcl-Xl, forward, 5'-TTCAGTCGGAAATGACCAGA-
CA-3', reverse, 5'-GAGGATGTGGTGGAGCAGAGA-3'; FAM-labelled probe, 5'-TGACCATCCACTCTACССТCCCACCC-3'; Fas, forward, 5'AAAAGCATTTTGAGCAGGAGAGTATT-3', reverse, $5^{\prime}$-GGCCATTAAGATGAGCACCAA-3'; JOE-labelled probe, 5'-CTAGAGCTCTGCCACCTCTCCATT-3'; FasL, forward, 5'-AAGAAAGTGGCCCATTTAACAG-3', reverse, 5'-AGAAAGCAGGACAATTCCATAGGT-3'; FAM-labelled probe, 5'CAACTCAAGGTCCATGCCTCTGG-3'; Survivin, forward, 5'-CTGCCTGGCAGCCCTTT-3', reverse, 5' -CTCCAAGAAGGGCCAGTTCTT-3'; FAMlabelled probe, 5'-TCAAGGACCACCGCATCTCTACATT-3'; c-FLIP, forward, 5'-GTGGAGACCCACCTGCTC-3', reverse, 5'-GGACACATCAGATTTATCCAAATCC-3', FAM-labelled probe; 5'-CTGCCATCAGCACTCTATAGTCCGAAACAA-3'; caspase-8, forward, 5'-AGGAGGAGATGGAAAGGGAACTT3', reverse, 5'-ACСТCAATTCTGATCTGCTCACTTCT-3'; JOE-labelled probe, 5'-CTCCCTACAGGGTCATGCTCTATCAGATTTCAG-3'; caspase-3, forward, 5'-AAGATCATACATGGAAGCGAATCA-3', reverse, 5'-CGAGATGTCATTCCAGTGCTTTTA-3'; FAM-labelled probe, 5'CTGGAATATCCCTGGACAACAGTTATAAA-3'; caspase-9, forward, 5'-TGCGAACTAACAGGCAAGCA-3', reverse, 5'-GAACCTCTGGTTTGCGAATCTC-3'; FAM-labelled probe, 5'-CAAAGTTGTCGAAGCCAACCCTAGAAAACCTTA-3'; bad, forward, 5'-CAGTGACCTTCGCTCCACATC-3', reverse, 5'-ACGGATCCTCTTTTTGCATAG-3'; JOE-labelled probe, 5'-ACTCCACCCGTTCCCACTGCCC-3'; Bax, forward, 5'-TTTCTGACGGCAACTTCAACT-3', reverse, 5'-GGTGCACAGGGCCTTGAG3'; JOE-labelled probe, 5'-TGTCGCCCTTTTCTACTTTGCCAGCA-3'; Bid, forward, 5'-GCTGTATAGCTGCTTCCAGTGTAG-3', reverse, 5' GCTATCTTCCAGCCTGTCTTCTCT-3'; JOE-labelled probe, 5'-AGCCCTGGCATGTCAACAGCGTTC-3'; Bim, forward, 5'-ACCACAAGGATTTCTCATGATACC-3', reverse, $5^{\prime}$-CCATATGACAAAATGCTCAAGGAA-3'; FAM-labelled probe, 5'-TAGCCACAGCCACCTCTCTCCCT-3'.

IL-21 assays and spiking. Serum IL-21 was measured using the eBioscience kit (catalog no. 88-7216-86) as per instructions. Plates were read using a microplate reader (model 680; Bio-Rad) at $450 \mathrm{~nm}$. Unstimulated and polyclonally stimulated $(1 \mu \mathrm{g} / \mathrm{ml}$ plate-bound anti-CD3 and $1 \mu \mathrm{g} / \mathrm{ml}$ soluble anti-CD28) PBMCs were spiked with $5 \mathrm{pg} / \mathrm{ml}$ and $20 \mathrm{pg} / \mathrm{ml} \mathrm{rhIL-21} \mathrm{(cata-}$ $\log$ no. 14-8219; eBioscience). $\mathrm{CD} 4^{+}$and $\mathrm{CD}^{+}$apoptosis and proliferation were assessed as described above.

IL-21 genotyping. In total, 4 SNPs, rs13151961, rs6822844, rs4833837, and rs6840978, which lie in a region of strong linkage disequilibrium, containing 4 genes, KIAA1109, ADAD1, IL2, IL21, on chromosome 4q27, were tested. All 4 SNPs were available as Applied Biosystems Assay-On-Demand products. SNP genotyping was performed using Applied Biosystems TaqMan methodology according to the manufacturer's recommended conditions. PCR was performed on Applied Biosystems 384-well 9700 Viper PCR machines, after which genotypes were determined on a 7900HT Sequence Detection System (Applied Biosystems), using Sequence Detection System Software version 2.1 (Applied Biosystems). Each individual was genotyped in duplicate. All individuals were additionally genotyped for the multiple sclerosis associated genetic factors HLA-DRB1*1501, rs2104286 (IL2RA), and rs6897932 (IL7R).

Statistics. Data were analyzed using SPSS Statistics version 12.0.1 for Windows. Following assessment for normality, parametric 2-tailed Student's $t$ tests or nonparametric Wilcoxon Mann-Whitney $U$ tests were performed. $P$ values are stated throughout the text; $P$ values of less than 0.05 were considered as statistically significant, modified by a Bonferroni correction where indicated.

\section{Acknowledgments}

The clinical work was performed in the Wellcome Trust Clinical Research Facility, Addenbrooke's Hospital. The authors thank Hayden Jones for his help in preparing the figures. The 
CAMMS223 trial was sponsored and funded by Genzyme and Bayer Schering Pharma. The CAMMS-224 trial was designed and performed at Department of Clinical Neurosciences, University of Cambridge, Addenbrooke's Hospital, and free alemtuzumab was supplied by Genzyme. Laboratory studies were funded by departmental funds. Patients were seen and treated on the Wellcome Trust Clinical Research Facility.

1. Coles, A., et al. 2006. The window of therapeutic opportunity in multiple sclerosis. J. Neurol. 253:98-108.

2. Coles, A.J., et al. 2008. Alemtuzumab vs. interferon beta-1a in early multiple sclerosis. N. Engl. J. Med. 359:1786-1801.

3. Coles, A.J., et al. 1999. Pulsed monoclonal antibody treatment and autoimmune thyroid disease in multiple sclerosis. Lancet. 354:1691-1695.

4. Chen, F., et al. 2005. Characteristics of autoimmune thyroid disease occurring as a late complication of immune reconstitution in patients with advanced human immunodeficiency virus (HIV) disease. Medicine (Baltimore). 84:98-106.

5. Daikeler, T., and Tyndall, A. 2007. Autoimmunity following haematopoietic stem-cell transplantation. Best. Pract. Res. Clin. Haematol. 20:349-360.

6. Jubault, V., et al. 2000. Sequential occurrence of thyroid autoantibodies and Graves' disease after immune restoration in severely immunocompromised human immunodeficiency virus-1-infected patients. J. Clin. Endocrinol. Metab. 85:4254-4257.

7. Ting, S.S., Ziegler, J.B., and Vowels, M.R. 1998. Acquired autoimmune thrombocytopenia postbone marrow transplantation for severe combined immunodeficiency. Bone Marrow Transplant. 21:841-843

8. Zandman-Goddard, G., and Shoenfeld, Y. 2002. HIV and autoimmunity. Autoimmun. Rev. 1:329-337.

9. Krupica, T., Jr., Fry, T.J., and Mackall, C.L. 2006. Autoimmunity during lymphopenia: a two-hit model. Clin. Immunol. 120:121-128.

10. Alderuccio, F., Toh, B.H., Tan, S.S., Gleeson, P.A., and van Driel, I.R. 1993. An autoimmune disease with multiple molecular targets abrogated by the transgenic expression of a single autoantigen in the thymus. J. Exp. Med. 178:419-426.

11. McHugh, R.S., and Shevach, E.M. 2002. Cutting edge: depletion of CD4+CD25+ regulatory $\mathrm{T}$ cells is necessary, but not sufficient, for induction of organ-specific autoimmune disease. J. Immunol. 168:5979-5983.

12. Powrie, F., Leach, M.W., Mauze, S., Caddle, L.B., and Coffman, R.L. 1993. Phenotypically distinct subsets of CD4+ T cells induce or protect from chronic intestinal inflammation in C. B-17 scid mice. Int. Immunol. 5:1461-1471.

13. Sakaguchi, S., Sakaguchi, N., Asano, M., Itoh, M., and Toda, M. 1995. Immunologic self-tolerance maintained by activated T cells expressing IL-2 receptor alpha-chains (CD25). Breakdown of a single mechanism of self-tolerance causes various autoimmune diseases. J. Immunol. 155:1151-1164.

14. King, C., Ilic, A., Koelsch, K., and Sarvetnick, N. 2004. Homeostatic expansion of T cells during immune insufficiency generates autoimmunity. Cell. 117:265-277.

15. Cox, A.L., et al. 2005. Lymphocyte homeostasis following therapeutic lymphocyte depletion in multiple sclerosis. Eur. J. Immunol. 35:3332-3342.

16. Bloom, D.D., et al. 2008. CD4+ CD25+ FOXP3+
Received for publication October 27, 2008, and accepted in revised form April 15, 2009.

Address correspondence to: Joanne L. Jones, Department of Clinical Neurosciences, Box 165, Addenbrooke's Hospital, Cambridge, United Kingdom. Phone: 01223-216751; Fax: 01223-336941; E-mail: jls53@medschl.cam.ac.uk. regulatory $\mathrm{T}$ cells increase de novo in kidney transplant patients after immunodepletion with Campath-1H. Am. J. Transplant. 8:793-802.

17. de Kleer, I., et al. 2006. Autologous stem cell transplantation for autoimmunity induces immunologic self-tolerance by reprogramming autoreactive $\mathrm{T}$ cells and restoring the CD4+CD25+immune regulatory network. Blood. 107:1696-1702.

18. Zhang, H., et al. 2005. Lymphopenia and interleukin-2 therapy alter homeostasis of CD4+CD25+ regulatory T cells. Nat. Med. 11:1238-1243.

19. Glas, J., et al. 2009. Novel genetic risk markers for ulcerative colitis in the IL2/IL21 region are in epistasis with IL23R and suggest a common genetic background for ulcerative colitis and celiac disease. Am. J. Gastroenterol. Online publication ahead of print.

20. International Multiple Sclerosis Genetics Consortium. 2008. Refining genetic associations in multiple sclerosis. Lancet Neurol. 7:567-569.

21. Yeo, T.W., et al. 2007. A second major histocompatibility complex susceptibility locus for multiple sclerosis. Ann. Neurol. 61:228-236.

22. Ge, Q., Bai, A., Jones, B., Eisen, H.N., and Chen, J. 2004. Competition for self-peptide-MHC complexes and cytokines between naive and memory CD8 $T$ cells expressing the same or different $T$ cell receptors. Proc. Natl. Acad. Sci. U. S. A. 101:3041-3046.

23. Ge, Q., Rao, V.P., Cho, B.K., Eisen, H.N., and Chen, J. 2001. Dependence of lymphopenia-induced $\mathrm{T}$ cell proliferation on the abundance of peptide/ MHC epitopes and strength of their interaction with T cell receptors. Proc. Natl. Acad. Sci. U. S. A. 98:1728-1733.

24. Kassiotis, G., Zamoyska, R., and Stockinger, B. 2003. Involvement of avidity for major histocompatibility complex in homeostasis of naive and memory T cells. J. Exp. Med. 197:1007-1016.

25. Cho, B.K., Rao, V.P., Ge, Q., Eisen, H.N., and Chen, J. 2000. Homeostasis-stimulated proliferation drives naive $\mathrm{T}$ cells to differentiate directly into memory T cells. J. Exp. Med. 192:549-556.

26. Goldrath, A.W., Bogatzki, L.Y., and Bevan, M.J. 2000. Naive T cells transiently acquire a memorylike phenotype during homeostasis-driven proliferation. J. Exp. Med. 192:557-564.

27. Murali-Krishna, K., and Ahmed, R. 2000. Cutting edge: naive $\mathrm{T}$ cells masquerading as memory cells. J. Immunol. 165:1733-1737.

28. Wu, Z., et al. 2004. Homeostatic proliferation is a barrier to transplantation tolerance. Nat. Med. 10:87-92.

29. Comi, C., et al. 2000. Defective T cell fas function in patients with multiple sclerosis. Neurology. 55:921-927.

30. Macchi, B., Matteucci, C., Nocentini, U., Caltagirone, C., and Mastino, A. 1999. Impaired apoptosis in mitogen-stimulated lymphocytes of patients with multiple sclerosis. Neuroreport. 10:399-402.

31. Shi, Y., et al. 2007. Critical regulation of CD4(+) $\mathrm{T}$ cell survival and autoimmunity by beta-arrestin
1. Nat. Immunol. 8:817-824.

32. Zang, Y.C., et al. 1999. Impaired apoptotic deletion of myelin basic protein-reactive $\mathrm{T}$ cells in patients with multiple sclerosis. Eur. J. Immunol. 29:1692-1700.

33. Vendrame, F., et al. 2005. Defective lymphocyte caspase-3 expression in type 1 diabetes mellitus. Eur.J. Endocrinol. 152:119-125.

34. Vendrame, F., et al. 2006. Impaired caspase-3 expression by peripheral $\mathrm{T}$ cells in chronic autoimmune thyroiditis and in autoimmune polyendocrine syndrome-2. J. Clin. Endocrinol. Metab. 91:5064-5068.

35. Gilleece, M.H., and Dexter, T.M. 1993. Effect of Campath-1H antibody on human hematopoietic progenitors in vitro. Blood. 82:807-812.

36. Yang, L., et al. 2008. IL-21 and TGF-[bgr] are required for differentiation of human TH17 cells. Nature. 454:350-352.

37. Ettinger, R., et al. 2005. IL-21 induces differentiation of human naive and memory B cells into antibody-secreting plasma cells. J. Immunol. 175:7867-7879.

38. Kuchen, S., et al. 2007. Essential role of IL-21 in $B$ cell activation, expansion, and plasma cell generation during CD4+ T cell-B cell collaboration. J. Immunol. 179:5886-5896.

39. Clough, L.E., et al. 2008. Release from regulatory $\mathrm{T}$ cell-mediated suppression during the onset of tissue-specific autoimmunity is associated with elevated IL-21. J. Immunol. 180:5393-5401.

40. Peluso, I., et al. 2007. IL-21 counteracts the regulatory $\mathrm{T}$ cell-mediated suppression of human CD4+ T lymphocytes. J. Immunol. 178:732-739.

41. Piao, W.H., et al. 2008. IL-21 modulates CD4+ $\mathrm{CD} 25+$ regulatory $\mathrm{T}$-cell homeostasis in experimental autoimmune encephalomyelitis. Scand. J. Immunol. 67:37-46.

42. Liu, Y., et al. 2008. A genome-wide association study of psoriasis and psoriatic arthritis identifies new disease loci. PLoS Genet. 4:e1000041.

43. van Heel, D.A., et al. 2007. A genome-wide association study for celiac disease identifies risk variants in the region harboring IL2 and IL21. Nat. Genet. 39:827-829.

44. Wellcome Trust Case Control Consortium. 2007. Genome-wide association study of 14,000 cases of seven common diseases and 3,000 shared controls. Nature. 447:661-678.

45. Zhernakova, A., et al. 2007. Novel association in chromosome 4q27 region with rheumatoid arthritis and confirmation of type 1 diabetes point to a general risk locus for autoimmune diseases. Am. J. Hum. Genet. 81:1284-1288.

46. Aubry, J.P., et al. 1999. Annexin V used for measuring apoptosis in the early events of cellular cytotoxicity. Cytometry. 37:197-204.

47. Lyons, A.B., Hasbold, J., and Hodgkin, P.D. 2001. Flow cytometric analysis of cell division history using dilution of carboxyfluorescein diacetate succinimidyl ester, a stably integrated fluorescent probe. Methods Cell Biol. 63:375-398. 